\title{
U-Slot Cut Rectangular Microstrip Antenna with a Large Ground Plane and a Thin Substrate
}

\author{
EVA KARLA GARZA-RESENDIZ ${ }^{1}$, MARIO REYES-AYALA ${ }^{1}$, \\ EDGAR ALEJANDRO ANDRADE-GONZALEZ ${ }^{1}$, HILARIO TERRES-PEÑA ${ }^{2}$ \\ ${ }^{1}$ Department of Electronics, ${ }^{2}$ Department of Energy \\ Metropolitan Autonomous University \\ San Pablo 180, Col. Reynosa Tamaulipas, Azcapotzalco (ZIP 02200), Mexico City \\ MEXICO
}

\begin{abstract}
It is very well known that the Rectangular Microstrip Antennas (RMA) are narrowband, but it is possible to enhance its bandwidth by cutting slots inside the patch. Some slots variations have been used to improve this important feature in modern mobile radiocommunication systems. Although U-slot antennas are employed in broadband applications, it is very important to consider the usage of a thick substrate with a low dielectric constant. In this paper, an RMA with a U-slot is presented and analyzed, which was built in a Printed Circuit Board (PCB) with a thin FR4 substrate for $800 \mathrm{MHz}$ to $900 \mathrm{MHz}$. The PCB that is necessary to fabricate the antenna is very low cost and it is conformable in many mobile terminals. The antenna was simulated in HFSS and measured using return loss and its antenna patterns.
\end{abstract}

Key-Words: - Rectangular microstrip antenna, mobile radio communication, higher mode, broadband antenna, antenna bandwidth, U-slot, antenna pattern, return losses.

Received: September 22, 2020. Revised: January 19, 2021. Accepted: February 14, 2021. Published: February 25, 2021.

\section{Introduction}

Since 1952 a lot of research reports have presented theoretical, simulation and experimental results around Rectangular Microstrip Antennas (RMA), where their disadvantages have been demonstrated in mobile radiocommunication [1], [2]. One of the most important limitations of microstrip antennas with rectangular or circular patches is a very low bandwidth (less than 3\%) [4], [5]. Both kinds of antennas are quite simple and do not require expensive manufacturing process [6], [7].

Triangular and bowtie microstrip antennas have a higher bandwidth than rectangular patches, but this parameter is still low for broadband mobile terminals in applications like Personal Communications Systems (PCS) [8], [9], [15].

Novel techniques were employed in order to enhance the frequency response of the patch antennas mentioned before [10], [11], [17]. Some of these approaches include several feedings methods and defected elements in their patches [12], [13], [14], [16], [18].

The usage of one or more slots inside the main patch in RMA has been used frequently with a relatively good results; but some restrictions have to consider decreasing its practical implementation [19]. The addition of U-slots requires a thick substrate with a low dielectric constant [20]. Besides, a short ground plane that is typically in Uslotted antennas narrows down the antenna gain and their main to back lobes ratios are normally low reducing the interference level and Electromagnetic Compatibility (EMC) in handheld pocket devices [21].

As a consequence of these problems, the U-slotted antennas have not been proposed for many broadband applications [22], [23].

In this paper, a new single U-slot antenna with a large ground plane is presented and analyzed. This antenna is fabricated in a very common non-expensive and thin FR4 substrate PCB. The antenna bandwidth that it is obtained in these conditions it is enough for the $800-900 \mathrm{MHz}$ standards.

This section is a brief review of the microstrip antennas and the main ideas about how to enhance the bandwidth of this antenna, where the addition of U-slots has been one of the main approaches. In section two, the design procedure of U-slotted microstrip antenna is adapted according to its implementation in the first cellular band and the new installation requirements in small terminals. The section three shows the simulation and experimental main results of the paper. The commercial computational tool developed by Ansoft that is called High Frequency Structure Simulation (HFSS) was used to evaluate the antenna performance with their original and optimized dimensions. In the section four, the main conclusions are presented and compared with some of the previous papers with U-slot antenna where thick substrate and short ground plane were employed. 


\section{Design Procedure of the U-Slot Antenna}

In this section, the mathematical model of the proposed antenna and its computation are presented in detail [1], [2], [3].

The very known RMA structure is shown in the Figures 1 and 2, where the most important parameters are indicated. $L$ is the large of the rectangular patch, mm; $W$ is the width of the rectangular patch, $\mathrm{mm} ; h$ is the thickness of the substrate of the PCB, mm; $t$ is the thickness of the copper layer of the $\mathrm{PCB}, \mathrm{mm}$; and, $\varepsilon_{\mathrm{r}}$ is the dielectric constant of the substrate of the PCB.

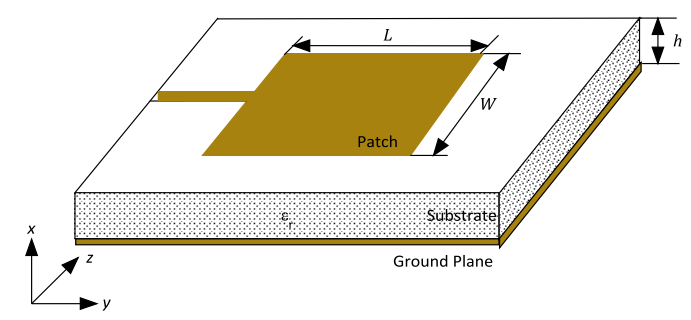

Fig.1 Rectangular patch antenna.

With the aim to obtain a low-profile antenna that is more compatible with the installation in all of sorts of vehicles or pocket terminals, the thickness of the antenna has to be lower than the large of the patch $(h<L)$. In the Figure 2, the side view of the structure is illustrated, where the drawing is not shown in the actual scale in order to see all the parameters of the structure.

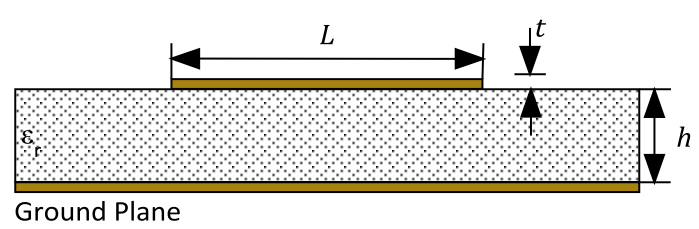

Fig.2 Antenna parameters in the side view.

The design procedure of the U-slot RMA antenna was calculated using a PCB with a standard thickness equal to $1.588 \mathrm{~mm}$ and a FR-4 substrate with a dielectric constant approximately equal to 4.4 .

The large of the rectangular patch is calculated using the equation (1), where $v_{0}$ is the phase velocity of light in the vacuum, $\mathrm{m} / \mathrm{s}$; and, $f_{\mathrm{r}}$ is the resonant frequency, $\mathrm{Hz}$; and, $\Delta L$ is the large correction, $\mathrm{mm}$.

$$
L+2 \Delta L \cong \frac{v_{o}}{2 \sqrt{\varepsilon_{r}} f_{r}} \cong 0.0837 \mathrm{~m}
$$

The width of the rectangular patch is calculated using the equation (2). It is obvious the relation of large and width of the rectangular patch of the antenna [1].

$$
W=1.5(L+2 \Delta L)=0.126 \mathrm{~m}
$$

The intensity of the electric field in the substrate is plotted in the Figure 3 for the dominant mode of the antenna [2].

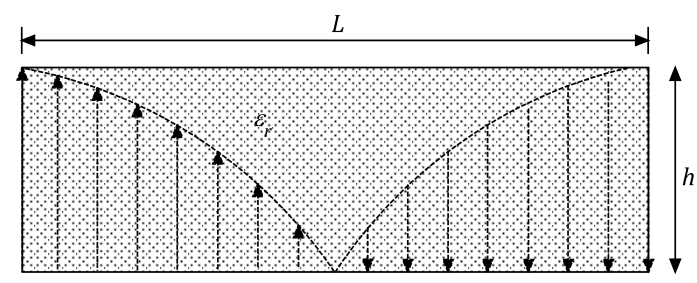

Fig.3 Flux lines of the electric field in the substrate of the antenna.

It is important to emphasize that there are flux lines that are present in the air above the rectangular patch. This phenomenon it is very complex to model and it is very useful an empirical method of approximation of the behavior of the fields. In the Figure 3 an effective dielectric constant is determined, which allows us to estimate the dielectric constant in an ideal homogeneous media [3].

$$
\varepsilon_{\text {reff }}=\frac{\varepsilon_{r}+1}{2}+\frac{\varepsilon_{r}-1}{2}\left(1+12 \frac{h}{W}\right)^{-\frac{1}{2}}
$$

Another impairment that is necessary to take into account in the antenna design is the presence of an irregular flux lines of the electric field in the edges of the rectangular patch of the antenna. This problem is called fringing and it is possible to be seen in the Figure 4.

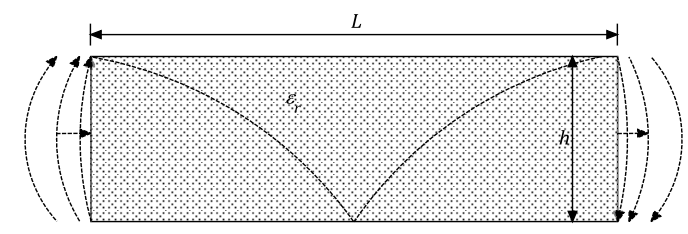

Fig. 4 Fringing effect in the edges of the patch of the antenna

The length of the actual rectangular patch has to be corrected in order to keep the resonant frequency. The Figure 5 shows the correction of the patch using $\Delta L$.

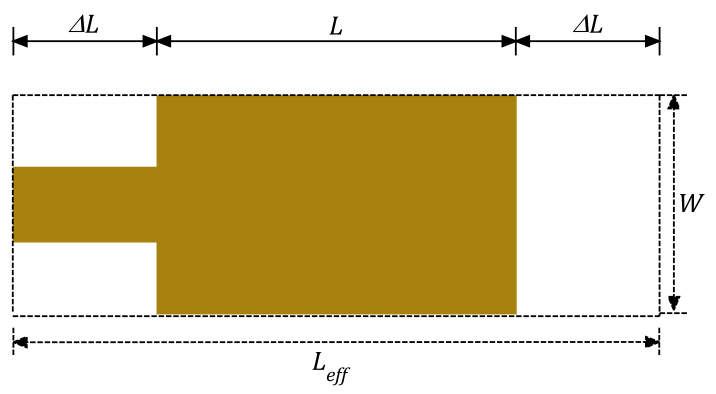

Fig. 5 Large correction in the rectangular patch of the antenna. 
The equation (4) determines the empirical correction of the actual large of the rectangular patch of the antenna.

$$
\Delta L=0.412 h \frac{\left(\varepsilon_{r e f f}+0.3\right)(W / h+0.264)}{\left(\varepsilon_{r e f f}-0.258\right)(W / h+0.8)}
$$

The actual large of the patch can be obtained using the equation (5).

$$
L=\frac{v_{0}}{2 f_{r \sqrt{\varepsilon_{r e f f}}}}-2 \Delta L=0.0837 \mathrm{~m}
$$

In this work, a coaxial probe was used in the antenna feed, because the receiver can be easily located below the bottom layer of the PCB. This way of feeding is also compatible with a large ground plane, which can reduce the size of the minor lobes of the antenna. In the Figure 6 the U-Slot antenna is illustrated.

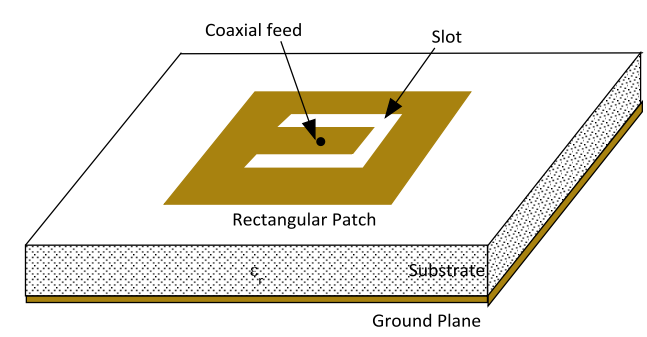

Fig. 6 U-slotted antenna with a coaxial probe feeding.

The geometry of the U- slot added in the rectangular patch is shown in Figure 7. The corresponding calculation was adapted in this article in order to reduce the thickness of the PCB.

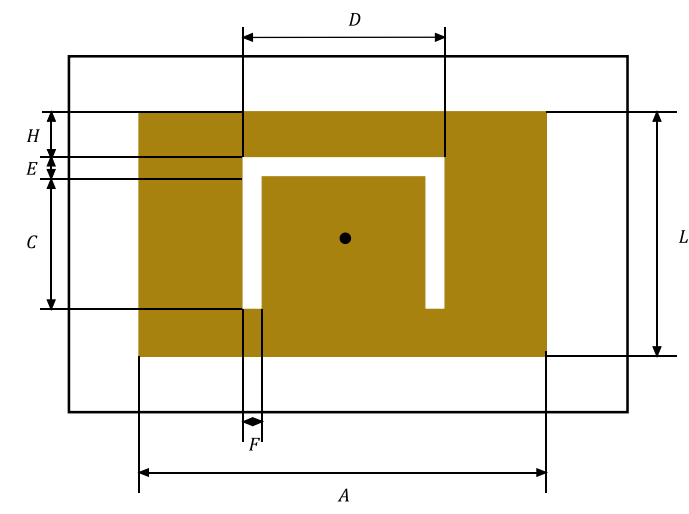

Fig. 7 U-slot dimensions.

The dimensions of the U-slot that are defined in the Figure 7 are determined by equations (6), (7), (8) and (9). Where $C$ is the large of the U-slot structure, $\mathrm{mm}$; $D$ is the width of the U-slot, $\mathrm{mm} ; E$ is width in the slot of the intermediate element of the $U$ structure, $\mathrm{mm}$; and, $F$ is the width of the slot of the U structure arms, $\mathrm{mm}$.

$$
E=F=\frac{v_{o}}{60 f_{r}}=0.005878 \mathrm{~m}
$$

$$
D=\frac{v_{o}}{\sqrt{\varepsilon_{\text {reff }}} f_{1}}-2(L+2 \Delta L-E)
$$

The equations (8) and (9) represent two design restrictions that have to be satisfied in order to verify the accuracy of the procedure.

$$
\begin{aligned}
& \frac{C}{W} \geq 0.30 \\
& \frac{C}{D} \geq 0.75
\end{aligned}
$$

The final design of the U-slot described before allows us to obtain a bandwidth less than the corresponding antennas with a thick substrate. Then, it is necessary to calculate the bandwidth of the new model presented in this article. This calculation can be computed using equation (10).

$$
B=\frac{f_{2}-f_{1}}{f r} \times 100 \%
$$

The resulting dimensions of the antenna that are calculated with the procedure explained are described in the Table 1 .

\begin{tabular}{|c|c|c|}
\hline \multicolumn{2}{|c|}{ Parameter } & Value (mm) \\
\hline $\begin{array}{c}\text { Large of the rectangular } \\
\text { patch }\end{array}$ & $L$ & 83.70 \\
\hline $\begin{array}{c}\text { Width of the rectangular } \\
\text { patch }\end{array}$ & $W$ & 126.10 \\
\hline Large of the U-slot structure & $C$ & 38.00 \\
\hline Width of the U-slot & $D$ & 22.20 \\
\hline $\begin{array}{c}\text { Width of the intermediate } \\
\text { element }\end{array}$ & $E$ & 5.88 \\
\hline $\begin{array}{c}\text { Width of the slot of the U } \\
\text { arms }\end{array}$ & $F$ & 5.88 \\
\hline $\begin{array}{c}\text { Distance to the edge of the } \\
\text { antenna }\end{array}$ & $H$ & 30.00 \\
\hline
\end{tabular}

Table 1. Dimensions of the antenna after the design procedure.

\section{Results}

The main results of this work are presented in this section. Using the structure described in Table 1 the frequency response has two resonant frequency $(767 \mathrm{MHz}$ and 866 $\mathrm{MHz}$ ), because the they are created by the rectangular patch and the U-slot respectively, see the Figure 8. 


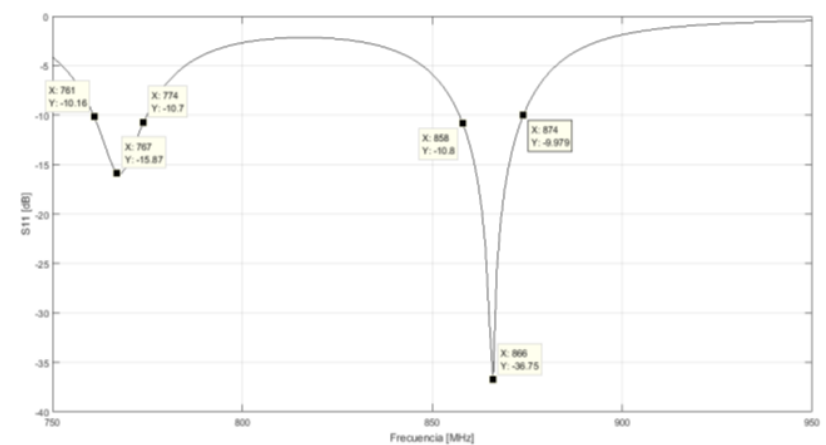

Fig. $8 S_{11}$ of the antenna without optimization procedure.

In order to get the original frequency interval for the first cellular band, the size of the rectangular patch and form of the U-slot were optimized modifying their dimension.

The optimized model of the antenna is shown in Figure 9 and the resulting parameters of the geometry of the antenna can be seen in the Table 2 .

It is important to note that the distance to the edge of the patch is zero, which is the most important difference with other single U-slot antennas that has been reported with thicker substrate and/or air or foamy substrates in the PCB.

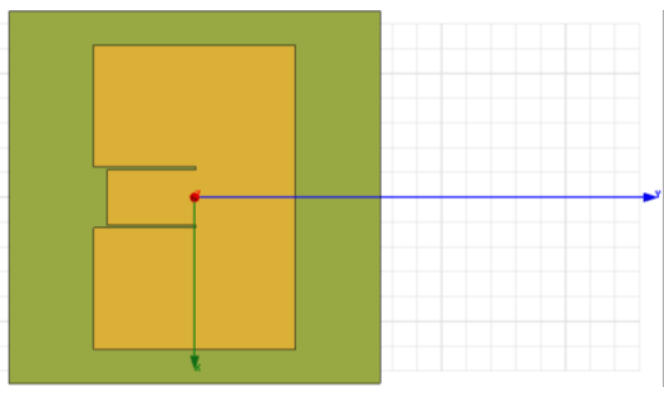

Fig. 9 Optimized model of the U-slot antenna.

\begin{tabular}{|c|c|c|}
\hline \multicolumn{2}{|c|}{ Parameter } & Value (mm) \\
\hline $\begin{array}{c}\text { Large of the rectangular } \\
\text { patch }\end{array}$ & $L$ & 81.70 \\
\hline $\begin{array}{c}\text { Width of the rectangular } \\
\text { patch }\end{array}$ & $W$ & 122.50 \\
\hline Large of the U-slot structure & $C$ & 35.90 \\
\hline Width of the U-slot & $D$ & 24.50 \\
\hline $\begin{array}{c}\text { Width of the intermediate } \\
\text { element }\end{array}$ & $E$ & 5.50 \\
\hline $\begin{array}{c}\text { Width of the slot of the U } \\
\text { arms }\end{array}$ & $F$ & 11.00 \\
\hline $\begin{array}{c}\text { Distance to the edge of the } \\
\text { antenna }\end{array}$ & $H$ & 0.00 \\
\hline
\end{tabular}

Table 2. Dimensions of the antenna after the structure optimization

The bandwidth of the antenna after the optimization is increased because the resonant frequencies are in only one matching interval, see equation (11).

$$
B=\frac{870-822}{843} \times 100 \%=5.69 \%
$$

The appropriate use of the two resonant frequencies allows us to use the antenna in broadband applications, because the modern mobile radio communications require a bandwidth greater than $3 \%$ in order to employ spread spectrum techniques in its the multiple access techniques. The return loss of the antenna is plotted in the Figure 10.

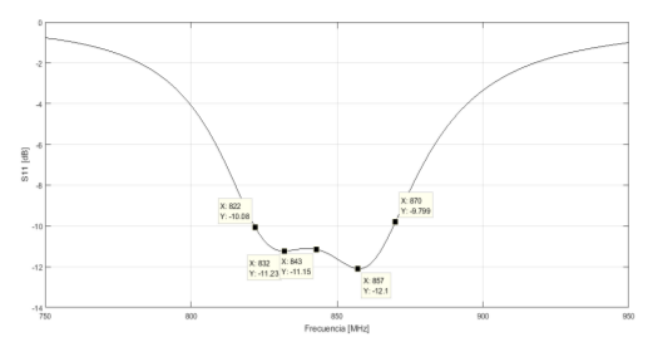

Fig. $10 S_{11}$ of the antenna after the optimization procedure.

The 3-D antenna pattern of the antenna that was obtained by simulation is shown in the Figure 11, where the final antenna directivity is equal to $3.41 \mathrm{~dB}$ approximately.

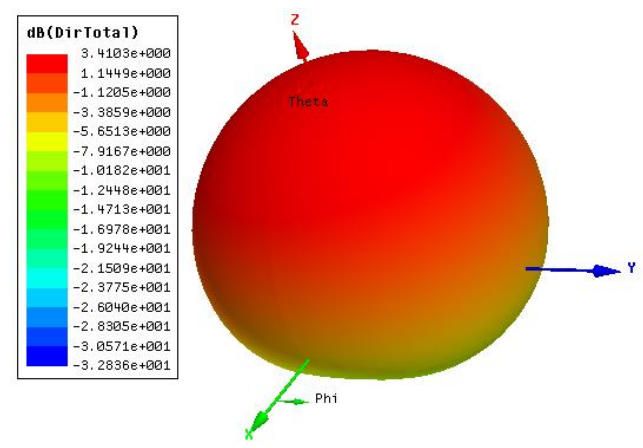

Fig. 11 3D Antenna pattern of the U-slot antenna after optimization procedure.

It is clear the wide main lobe and a low back lobe of the U-slot antenna that could be used in mobile communications. In addition to this, It is important to see the quasi-omnidirectional pattern in the azimuthal plane $(\theta$ $=90^{\circ}$ ) that is compatible with PCS in order to keep communication in mobile systems.

In the Figure 12 the antenna pattern in the E-Plane is illustrated for $\phi=0^{\circ}$, where the antenna gain and Half Power Beamwidth are approximately equal to $3.4 \mathrm{~dB}$ and $100^{\circ}$, respectively. Besides the major lobe to back lobe ratio es greater than $25 \mathrm{~dB}$. 


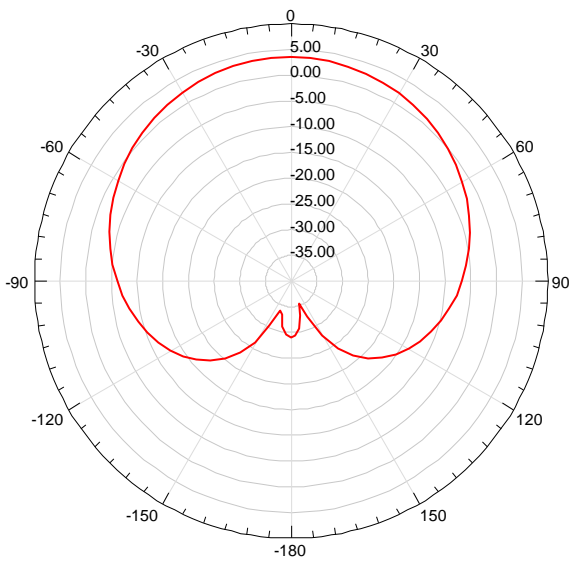

Fig. 12 2-D Antenna pattern $\left(\phi=0^{0}\right)$.

In the Figure 13 the antenna pattern in the E-Plane is illustrated for $\phi=90^{\circ}$. In this case, the HPBW is approximately equal to $95^{\circ}$ and the and the back lobe is absent.
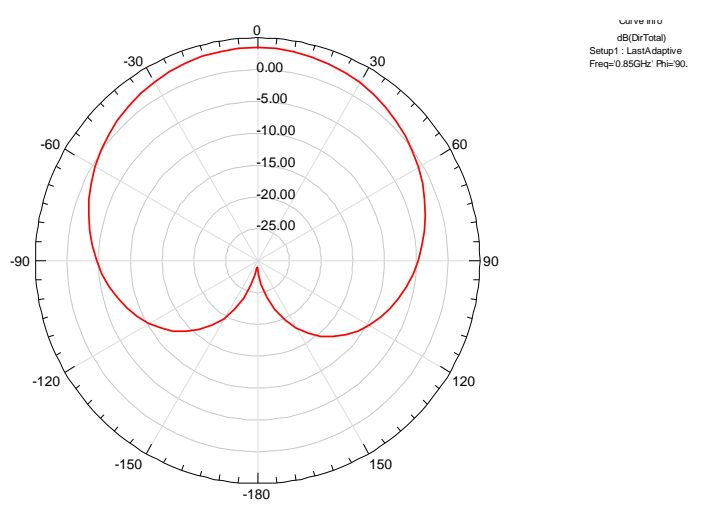

Fig. 13 2-D Antenna pattern $\left(\phi=90^{\circ}\right)$.

The optimized variation of the U-slot antenna was built and measured. In the Figure 14 the implemented antenna is illustrated.

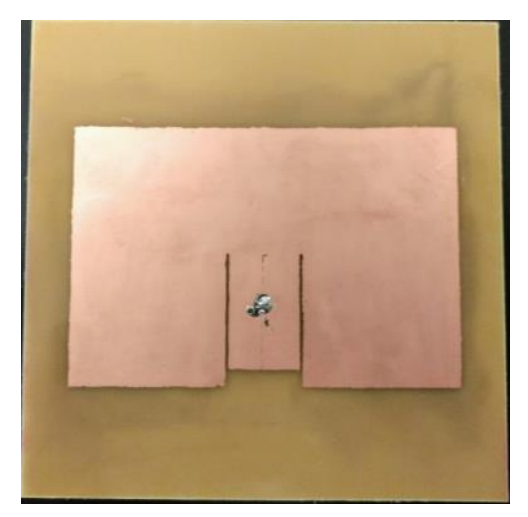

Fig. 14 U-slot antenna.

The resulting bandwidth obtained experimentally it is computed in equation (12), where it is clear that the bandwidth of the proposed antenna is broadband $(>3 \%)$ and close to the simulation results.

$$
B=\frac{(872-837) \mathrm{MHz}}{852 \mathrm{MHz}} \times 100 \%=4.1 \%
$$

The return losses were measured using a Network Analyzer, see Figure 15.

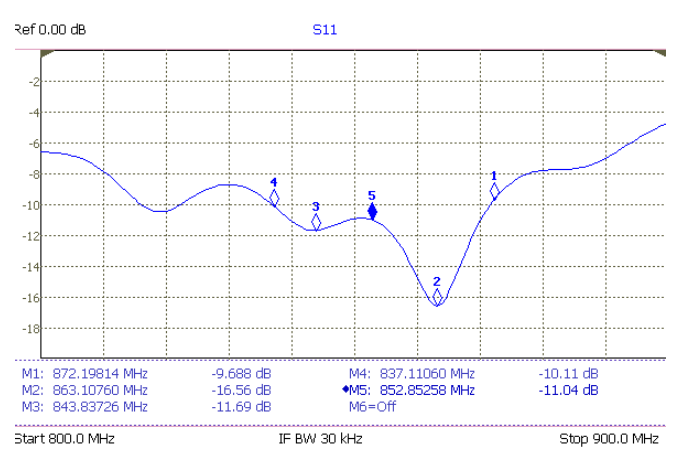

Fig. 15 Return losses $\left(S_{11}\right)$ of the implemented antenna.

Finally, the antenna pattern of the U-slot antenna was measured using a near-field scanner that interpolates the far-field behavior of the antenna, see the Figure 16.

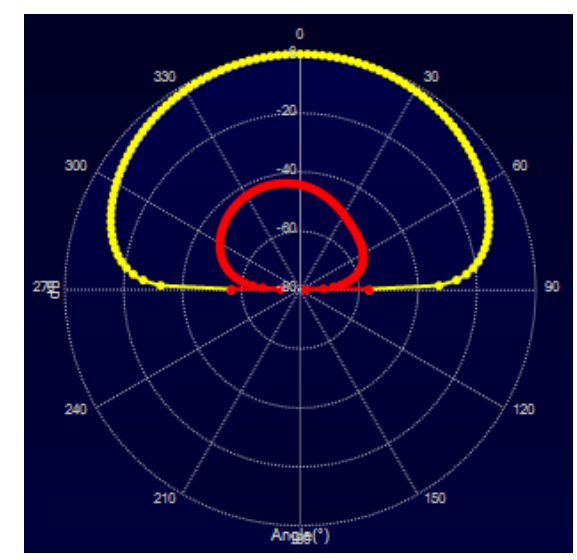

Fig. 16 Antenna pattern of the implemented U-slot antenna.

\section{Conclusion}

An analysis of a single U-slotted microstrip rectangular antenna is presented in this paper. The simulation and experimental results show that the antenna is broadband and can be used in the first band of Personal Communications Systems.

Other U-slot variations of used in this kind of antennas are impractical in many handset terminals, because its use implies a thick substrate with a special dielectric constant with a $h$ ranging from $3 \mathrm{~mm}$ to $7 \mathrm{~mm}$ [23], [25].

One of the most important features of the proposed antenna is the use of a very common PCB with a non-expensive FR-4 substrate and a standard thickness $(h=1.588 \mathrm{~mm})$.

The resulting bandwidth $(4.1 \%)$ and antenna gain $(3.4 \mathrm{~dB})$ are compatible with many applications in mobile radiocommunication systems and a good electromagnetic compatibility [24], [26].

The use of a regular cheap and commercial PCB in U-slot antennas is now evaluated in dual or multiple slots inside the 
rectangular patches as a continuation of this work with the aim of using the antenna in multiband applications [31].

Another goal that we are working in is to improve the antenna in order to get dual polarization using asymmetrical elements in the patch, cutting the edges in the corners or adding defected structures in the ground plane [27], [28], [29], [30].

\section{References:}

[1] C. A. Balanis, Antenna Theory, 3rd Edition, New Jersey, John Wiley \& Sons, 2016.

[2] J. L. Volakis, Antenna Engineering Handbook, McGrawHill, 5th Edition, 2019.

[3] D. M. Pozar, Microwave Engineering, 4th Edition, New Jersey, John Wiley \& Sons, 2012.

[4] R. E. Munson, Conformal Microstrip Antennas and Microstrip Phased Arrays, IEEE Transactions on Antennas and Propagation, Vol. AP-22, No. 1, January, 1974, pp. 74 -78 .

[5] J. Q. Howell, Microstrip Antennas, IEEE Transactions on Antennas and Propagation, Vol. AP-23, No. 1, January, 1975, pp. $90-93$.

[6] D. S. Chang, Analytical Theory of an Unloaded Rectangular Microstrip Patch, IEEE Transactions on Antennas and Propagation, Vol. AP-29, No. 1, January, 1981 , pp. $54-62$.

[7] J. R. James, P. S. Hall, C. Wood, A. Henderson, Some Recent Developments in Microstrip Antenna Design, IEEE Transactions on Antennas and Propagation, Vol. AP-29, No. 1, January, 1981, pp. $124-128$.

[8] K. W. Loi, S. Uysal, M. S. Leong, Design of a wideband microstrip bowtie patch antenna, IEE Proceedings Microwaves Antennas and Propagation, Vol. 145, No. 2, April, 1998, pp. 137 - 140.

[9] W. F. Richards, Y. T. Lo, D. D. Harrison, "An Improved Theory for Microstrip Antennas and Applications, IEEE Transactions on Antennas and Propagation, Vol. AP-29, No. 1, January, 1981, pp. $38-46$.

[10] S. S. Hong, Y. T. Lo, Single-Element Rectangular Microstrip Antenna for Dual-Frequency Operation, Electronics Letters, Vol. 19, No. 8, August, 1983, pp. 298 -300 .

[11] H. Pues and A. Van de Capelle, Accurate TransmissionLine Model for the Rectangular Microstrip Antenna, IEE Proceedings, Vol. 131, No. 6, December, 1984, pp. 334 340.

[12] E. Chang, S. A. Long, W. F. Richards, An Experimental Investigation of Electrically Thick Rectangular Microstrip Antennas, IEEE Transactions on Antennas and Propagation, Vol. 34, No. 6, June, 1986, pp. 767 - 772.

[13] D. M. Pozar, An Update on Microstrip Antenna Theory and Design Including Some Novel Feeding Techniques, IEEE Transactions on Antennas and Propagation Society Newsletter, Vol. 28, October, 1986, pp. 5 - 9.

[14] D. Edward, D. Rees, A Broadband Printed Dipole with Integrated Balun, Microwave Journal, 1987, pp. 339 - 344.

[15] J. S. Chen, K. L. Wong, A Single-Layer Dual-Frequency Rectangular Microstrip Patch Antenna using a Single Probe Feed, Microwave and Optical Technology Letters, Vol. 11, No. 2, February, 1996, pp. $83-84$.

[16] K. W. Loi, S. Uysal, M. S. Leong, Design of a wideband microstrip bowtie patch antenna, IEE Proceedings Microwaves Antennas and Propagation, Vol. 145, No. 2, April, 1998, pp. $137-140$.
[17] Y. W. Jang, Broadband Cross-Shaped Microstrip-Fed Slot Antenna, Electronics Letters, Vol. 36, No. 25, December, 2000, pp. $2056-2057$.

[18] Y. Tawk, K. Y. Kabalan, A. El-Hajj, C. G. Christodoulou, J. Constantine, A Simple Multibeam Printed Bowtie Antenna, IEEE Antennas and Wireless Propagation Letters, Vol.7, February, 2008, pp. $57-560$.

[19] T. Huyn, K. F. Lee, Single Layer Single Patch Wideband Microstrip Antenna, Electronics Letters, Vol. 31, No. 16, August, 1995, pp. $1310-1312$.

[20] M. Clenet, L. Shafai, Multiple Resonances and Polarization of U-Slot Patch Antenna, Electronics Letters, Vol. 35, No. 2, January, 1999, pp. $101-102$.

[21] Y. L. Chow, Z. N. Chen, K. F. Lee, K. M Luk, A Design Theory on Broadband Patch Antennas with Slot, IEEE Antennas and Propagation Society International Symposium Digest, Vol. 2, 1993, pp. 1124 - 1127.

[22] K. F. Lee, S. L. S. Ynag, A. A. Kishk, K. M Luk, The versatile U-Slot Patch Antenna, IEEE Antennas and Propagation Magazine, Vol. 52, No. 1, February 2010, pp. 71-88.

[23] S. Weigand, G. H. Huff, K. H. Pan, J. T. Bernhard, Analysis and Design of Broad-Band Single-Layer Rectangular U-Slot Microstrip Patch Antennas, IEEE Transactions on Antennas and Propagation, Vol. 51, No. 3, March 2003, pp. 457-468.

[24] A. A. Deshmukh, K. P. Ray, Analysis of Broadband Variations of U-Slot Cut Rectangular Microstrip Antennas, IEEE Antennas and Propagation Magazine, Vol. 57, No. 2, April, 2015, pp. 181 - 193.

[25] M. Khan, D. Chatterjee, Analysis of Reactive Loading in a U-Slot Microstrip Patch Using the Theory of Characteristic Modes, IEEE Antennas and Propagation Magazine, Vol. 60, No. 6, December 2018, pp. 88 - 97.

[26] H. R. Bae, S. O. So, C. S. Cho, A Crooked U-Slot DualBand Antenna with Radial Stub Feeding, IEEE Antennas and Wireless Propagation Letters, Vol. 8, December 2009, pp. $1435-1438$.

[27] P. Y. Qin, A. R. Weily, Y. J. Guo, C. H. Liang, Polarization Reconfigurable U-Slot Patch Antenna, IEEE Transactions on Antennas and Propagation, Vol. 58, No. 10, October 2010, pp. $3383-3388$.

[28] K. Y. Lam, K. M. Luk, K. F. Lee, H. Wong, K. Bo, Small Circularly Polarized U-Slot Wideband Patch Antenna, IEEE Antennas and Wireless Propagation Letters, Vol. 10, February 2011, pp. $87-90$.

[29] P. Nayeri, K. F. Lee, A. Z. Elsherbeni, F. Yang, Dual-Band Circularly Polarized Antennas Using Stacked Patches With Asymmetric U-Slots, IEEE Antennas and Wireless Propagation Letters, Vol. 10, May 2011, pp. 492 - 495.

[30] H. Y. Chen, Y. Tao, Performance Improvement of a U-Slot Patch Antenna Using a Dual-Band Frequency Selective Surface With Modified Jerusalem Cross Elements, IEEE Transactions on Antennas and Propagation, Vol. 59, No. 9, September 2011, pp. $3482-3486$.

[31] S. Liu, S. S. Qi, W. Wu, D. G. Fang, Single-Layer SinglePatch Four-Band Asymmetrical U-Slot Patch Antenna, IEEE Transactions on Antennas and Propagation, Vol. 62, No. 9, September 2014, pp. 4895 - 4899.

This work was supported by the research project EL002-18 in the Metropolitan Autonomous University in Mexico City.

\section{Creative Commons Attribution License 4.0 (Attribution 4.0 International, CC BY 4.0)}

This article is published under the terms of the Creative Commons Attribution License 4.0

https://creativecommons.org/licenses/by/4.0/deed.en_US 